Journal of Social Sciences 2 (4): 108-112, 2006

ISSN 1549-3652

(C) 2006 Science Publications

\title{
Improving the Psychology Undergraduate Curriculum in Developing Countries: A Personal Note with Illustrations from Brazil
}

\author{
${ }^{1}$ Charles I. Abramson and ${ }^{2}$ Amauri B. Bartoszeck \\ ${ }^{1}$ Oklahoma State University, Laboratory of Comparative Psychology and Behavioral Biology \\ Departments of Psychology and Zoology, 215 North Murray, Stillwater, OK 74078, USA \\ ${ }^{2}$ Universidade Federal do Paraná, Department of PhysiologyCx. Postal 2276 \\ 80011-970 Curitiba, PR, Brazil
}

\begin{abstract}
In this article we suggest various ways in which the undergraduate curriculum for psychology students can be improved in developing countries. Suggestions based on the author's experience in the northeast of Brazil include forming psychology clubs, creating community outreach programs, establishing a human subject pool, skills training, developing research-based courses and seeking outside funding.
\end{abstract}

Key words: Brazil, teaching, psychology

\section{INTRODUCTION}

For the past 10 years the first author has been regularly visiting the northeast of Brazil as part of an on-going investigation into the comparative psychology of Africanized honey bees ${ }^{[1,2]}$. More recently, we have begun a new line of research to determine whether psychology students in Brazil consider psychology on the same level with such natural sciences as chemistry, biology and physics. The answer depends, in part, on which part of Brazil the results were obtained. Students in the northeast, for example, do not consider psychology to be on the same level as a natural science while those in the south generally agree that psychology can be considered a natural science ${ }^{3,4]}$.

In the course of these investigations the first author has had the opportunity and privilege of working with a wide range of Brazilian psychologists from several universities in the states of Paraiba and Paraná. During these visits he discussed with undergraduate psychology students and their professors ways in which the training of students might be enhanced.

This article is the result of these conversations and offers some personal reflections on how the psychological training of undergraduates can be improved in Brazil, particularly in the northeast and in other developing countries. The suggestions in this article will also be useful to any discipline in the social sciences.

Psychology students in Brazil focus their efforts by taking psychology related courses with few electives. This is different than in the United States (U.S.) were many psychology majors receive a liberal arts education. Brazilian students graduate as a Bachelor of Psychology (8 semesters of studies), which is equivalent to a Bachelor of Sciences in Psychology in the U.S. or receive a Diploma of Psychology after ten semesters of study. Brazilian undergraduate psychology majors typically sit for a 5 year undergraduate program, studying disciplines such as neurophysiology, psychobiology, social, experimental, developmental, health and organizational psychology ${ }^{\left[{ }^{[5]}\right.}$.

We would like to note that some of our suggestions may not be appropriate for a specific university and some may already be utilized. Our goal is to share with you what has worked in the senior author's department at Oklahoma State University and to stimulate discussions among students and faculty in the reader's home institution.

Our suggestions can roughly be classified into 4 categories. The first is the recognition that the psychology undergraduate possess a range of skills not normally found in any one science major. Within this category are brief discussions on the skills a psychology graduate should possess, development of teaching laboratories and research experience courses and creation of a human subject pool.

The second category contains suggestions on how psychology students can obtain jobs upon graduation. The third category suggests ways in which psychology can be made more relevant to the general public. These "outreach programs" include creating psychology clubs and science fairs, linking community service to coursework and conducting "psychology as science shows" which is seldom done in Brazil.

The fourth category provides suggestions on how professors and students can obtain outside funding for research and teaching. Here, we propose the development of "sister" relationships among psychology departments and the seeking of funding from such organizations as International Rotary and the National Science Foundation.

Corresponding Author: $\quad$ C. I. Abramson, Laboratory of Comparative Psychology and Behavioral Biology, Departments of Psychology and Zoology, 215 N. Murray, Stillwater, OK 74078, Tel: (405) 744-7492, Fax: (405) 744-8067 
Category 1: Skills a psychology graduate should possess: In an interesting paper Hayes ${ }^{[6]}$ describes several skills that a psychology student should possess upon graduation and these are repeated below. Students from other disciplines may have acquired similar skills but what distinguishes the psychology student from other undergraduate science majors is the number and variety of such skills. Students that do not have these skills should acquire them. One way to estimate the quality of a graduate's knowledge is to develop a psychology skills test. There are several available in the U.S. and it should not be difficult to construct a similar test designed explicitly for psychology students in the reader's home institution.

The skills of a psychology undergraduate: The first skill is literacy. Students should be literate and trained to express themselves in writing. By writing research reports as class assignments and/or in their capacity as research assistants, students can prepare standardized reports of value to businesses and commercial enterprises. Quantitative ability is a second skill that should be possessed by psychology undergraduates. Although some psychology departments in developing countries require some type of quantitative training, we believe it should be more intensive. Such ability is useful in interpreting and summarizing data. Moreover, students with quantitative ability can evaluate a variety of research reports and summarize scientific literature. A third ability that should be possessed by psychology students is computer literacy. Computers are now standard equipment in any psychology laboratory in the U.S. and Europe. Many Brazilian psychology undergraduate laboratories are moving toward this. It is more common to find computers in $\mathrm{Ph}$. D. programs than in undergraduate programs, however. Thus, learning how to operate and interface a computer for psychological experimentation gives the graduate another useful skill - especially where data processing and statistical analysis are concerned.

Hayes ${ }^{[6]}$ describes several other skills that should be possessed by a psychology undergraduate student. These can be placed under the broad category of research skills. Successful Brazilian students should be trained in principles of research including naturalistic observation, quasi-experimental design, experimental design and survey construction. Critical thinking and problem solving ability is also learned in a research design course. Moreover, Brazilian psychology students should be trained in library and internet research, even if funding restrictions precluded renewal of journal subscriptions. A useful library training exercise for psychology students is already available ${ }^{[7]}$.

Development of courses in which students gain research experience: With budget constraints forcing many departments to cut spending and requiring faculty to increase their teaching loads it might not be practical to offer a wide range of courses to increase the skills needed to make psychology graduates in developing counties highly competitive on the job market or eligible for advanced training at the Master's or Doctoral level. In the first author's department, one of the most popular courses for the serious psychology student is a practical research course. Here, students work directly with a faculty member or graduate student on a specific research project. Duties include, but are not limited to, preparing literature summaries, running experiments, analyzing data, scoring questionnaires and preparing work for publication. Such a course is not only useful for students but also for faculty seeking research assistants.

Development of teaching laboratories: Most psychology departments either in U.S., Europe and Brazil maintain laboratories directed by professors engaged in research. Student involvement in such laboratories is generally restricted to those under direct supervision of the laboratory director. A second type of laboratory that can be maintained by a department is a teaching laboratory. The difference between the two is that the teaching laboratory is opened to all students. It is here where students apply the basics of statistical design to their own data sets, run commercially available software packages on a variety of experiments in social psychology, perception, learning and developmental psychology. A teaching laboratory is ideal for departments needing to provide skills training for their students.

The first author has developed a website with free software that can be downloaded for experiments in perception and cognitive psychology. The site also contains software for recording observations, a pronunciation guide for names in psychology and classroom tested exercises in animal learning using vertebrates and invertebrates. The address of the site is: http://psychology.okstate.edu/museum/index.html. He has also published software using computer-assisted instruction suitable for a course on learning. The software contains several simulations ${ }^{[8]}$ and is available on request.

Establishing an undergraduate research pool: The first author was struck by how little research is performed in some Brazilian psychology departments. Although $54 \%$ of the students in a northeast Brazilian survey strongly agreed that psychology is a science, in contrast only $26 \%$ of the sample strongly agreed that research is necessary and that training in methodology is important ${ }^{[4]}$. On the other hand, a southern sample generally agreed (75\%) that psychology should be considered in the same category as biology, chemistry and physics and values research $(65.7 \%)$ in solving psychological problems relatively high ${ }^{[3]}$.

The heavy emphasis on teaching and service is certainly one factor that makes it difficult for professors 
to find time for research in developing countries. Another, in our opinion, is the lack of a departmental structure in which faculty have access to research services and a third is lack of funding from Federal agencies or state foundations such as $\mathrm{CNPq}$ and Araucária Foundation-Paraná in Brazil. On the assumption that conducting research is considered important by psychologists in developing countries, a human subject pool can easily be created. Students receive course credit for participating and have the additional benefit of experiencing psychological research. Moreover, faculty can recruit student research assistants to help in conducting an experiment. In this way, a student receives practical research experience in experimental design and learns how to enter and analyze data and prepare research reports. Such a situation is ideal when combined with a practical research course.

Category 2: Suggestions on how psychology students can obtain jobs upon graduation: A sure sign of a healthy psychology curriculum is the ability of graduates to obtain jobs and/or receive advance training at the graduate level. Nothing can reduce the morale of a department more than by the inability of its students to apply or advance their education. A student who sees no future is a detriment to his/her department.

Jobs in psychology: An undergraduate psychology major possessing most, if not all, of the skills mentioned in Category 1 (see above) is in a good position to secure a job after graduation. In speaking with Brazilian undergraduate psychology students the first author was surprised to learn that few students realized the range of job possibilities. These jobs include statistical, guidance, rehabilitation and/or vocational consultant, technical editor, personnel selection, advertising designer, public relations professional, consumer affairs official, market research director, research assistant, behavioral engineer, training new employees, testing job applicants, corrections officer and of course, professor and teacher $^{[9]}$. Clearly, some effort must be made to acquaint students with the many possibilities.

Creating a database of psychology jobs: A method to ensure that students learn of job possibilities is to create a job database. One of the complaints the first author repeatedly hears from students is the lack of jobs in psychology. We believe part of the problem is that students do not have a clear vision of the many opportunities available to them. As we mentioned in the section on "Skills a Psychology Student Should Possess" psychology students have a broad range of skills not found in the graduates of many other scientific disciplines. One suggestion is for the department (or psychology club - see below) to maintain a listing of available jobs. This list should be regularly updated. Another suggestion is to publish a newsletter or website listing job possibilities available to psychology graduates.

Establishing a departmental alumni list: One of the most common methods of obtaining jobs in psychology is through "networking." Psychology departments can maintain mailing lists of their graduates. These graduates can receive regular updates about departmental news and events. Moreover, psychology alumni can be used to help students secure entry level positions and as a source for departmental donations of equipment, funds and/or time.

Category 3: Ways in which psychology can be made more relevant to the general public: In conversations with community leaders, the first author was somewhat disappointed that so few seem to understand the vital role that psychology plays in community affairs. Many leaders appear to have the impression that in times of pressing economic and environmental concerns psychology is unnecessary and a waste of limited financial and educational resources. From our perspective, it is precisely during such times that the science of psychology provides the greatest benefit. It is our opinion that psychology departments must do a better job of making community leaders and the general public aware of the many contributions we can offer. Such awareness has the benefit of increasing morale of students and faculty, lead to greater recognition by government officials, increase funding by state and federal agencies and increase the potential job market for psychology graduates.

Creating a psychology club: Psychology is one of the more popular majors on college campuses. Such popularity often produces a professor/student ratio too high to have any meaningful contact with all but a handful of students. One way to provide meaningful contact is to encourage students to form a "psychology club." Satterfield and Abramson ${ }^{[10]}$ provide detailed instructions on forming a club, club activities, recruiting members, structuring the club and securing funds. What can be said here is that club activities range from debates on contemporary issues, to providing mini-workshops. These workshops focus on, for instance, resume building, ethics, writing for publication, grant seeking, evaluating manuscripts, time management, preparing conference posters and oral presentations. Moreover, students can practice job interview skills, learn to prepare applications for graduate school and present a film series on psychological topics. Social events can also be planned where students and faculty can meet outside of the formal confines of the classroom. One popular club activity is the annual selection of the department's outstanding psychology faculty member and outstanding student. The award winners receive a 
certificate from the club presented at, for example, an annual awards banquet.

One of the major challenges to any club is recruiting and maintaining membership. Recruitment tools include club applications, schedule of events and activity announcements posted around campus. Club events are also announced during class. The membership application contains such information as name and address, special skills the applicant may possess and what committee the student may like to serve on (i.e., membership, philanthropy, scholarship and programs). Members post publicity about club activities, recruit new members and provide feedback and suggestions for future activities.

The structure of the club includes a faculty advisor and club president, vice-president, secretary and treasurer. Students may also serve as publicity chair and fundraising chair. A club constitution should also be written clearly defining the responsibilities of all the officers.

Linking appropriate courses to community service: Another suggestion to make the public aware of the many contributions of psychology to public welfare is to link appropriate courses with public service. In the same way that establishing a human subject pool helps students better understand the value of psychological research so too does linking a course to community needs help members of the community better understand psychology and its role in society. These activities include volunteering at a mental health facility and participating in mental health related activities such as "hotlines" and crisis centers.

Creating a "Psychology Fair": To make the general public and community leaders aware of the many contributions psychologists make is to hold an annual "Psychology Fair." The fair can be co-sponsored by the psychology club and department. Activities include games (e.g., navigating a maze), controlling the galvanic skin response, biofeedback training, presenting various visual illusions, examples of the scientific method relating to psychology, presenting the history of psychology and discussing what psychologists do. Particularly useful are poster presentations of student and faculty research. More serious activities include screening for depression and administering stress tests. We are aware that many professors and instructors may not be very enthusiastic to embrace a cause like the above due to heavy teaching load and low salaries. However, it deserves a try!

Conducting "Psychology as Science Shows": A version of the "Psychology Fair" that the first author has used most successfully is what he has called the "Psych-mobile ${ }^{\mathrm{TM}}$." The Psych-mobile ${ }^{\mathrm{TM}}$ is essentially the Psychology Fair on wheels that visits high school or secondary school classrooms. Magic tricks can be performed demonstrating principles of the scientific method, the varieties of psychology can be discussed and various types of visual illusions presented. Students also perform hands-on psychology experiments in animal and human behavior. In this way, students at the pre-college level learn the benefits of psychology. Psychology undergraduates and graduate students can also be trained to perform these shows. There is also something to be said about strengthening the bond between universities and high schools.

Category 4: Suggestions on how professors and students can obtain outside funding for research and teaching: One of the biggest surprises in speaking with Brazilian academic psychologists is the lack of knowledge about how to find outside funding.

Applying for grants and seeking collaborators: There are many international agencies that fund both research and teaching related projects. In addition to Brazilian agencies such as CAPES and CNPq, many private foundations provide money for research and student stipends. The International Rotary Club, for example, has several grant programs that are underutilized. We also suggest that psychologists consider applying to the National Science Foundation (NSF). Applications and program descriptions are available on-line. Of special interest is the NSF Research Experience for Undergraduates program (REU). The NSF-REU program is for students who are interested in non-mental health research (i.e., experimental and comparative psychology).

The Research Experience for Undergraduates programs are aimed at students who would not otherwise have the opportunity to gain independent research experience ${ }^{[11]}$. Such students may come from institutions with limited research facilities and/or be from underrepresented groups. There is a section of this program that deals specifically with international collaboration. The first author, for example, has been part of the NSF-REU program for several years and has brought American students to Brazil, Venezuela and Turkey to engage in collaborative research projects. Moreover, many grants have an international component in which the researcher can provide funds for collaborative efforts. We suggest that such programs are an untapped resource for psychologists and students in developing countries.

Developing relationships among other psychology departments and laboratories: Related to the idea of seeking international funding is creating sustainable collaborative agreements and "sister relationships" with other psychology departments in, for example, the U.S. and Europe. American psychology has often been criticized for its lack of international integration ${ }^{[12,13]}$ and efforts are underway to increase international collaboration. Often all it takes to establish 
collaborative agreements is an initial contact. The first author has several such agreements with Brazilian departments and, in his role as Head of the "Brazilian Desk" at the Oklahoma State University School of International Studies, is seeking more. These agreements can lead to cooperative funding opportunities, professor and student exchanges and money for the development of teaching laboratories and improvement of research facilities. Such efforts are an untapped resource and should be taken advantage of by academic psychologists in developing countries.

\section{CONCLUSION}

This article provides some personal reflections on how the psychology curriculum in developing countries, as illustrated by our experience in Brazil, can be improved. We would encourage psychology departments and their professors to try at least some of our suggestions especially the psychology clubs, research experience courses and international collaborations. The effort in implementing the ideas suggested here is not great but the results are.

\section{REFERENCES}

1. Abramson, C.I. and I.S. Aquino, 2002. Behavioral studies of learning in the Africanized honey bee (Apis mellifera L.). Brain Behavior and Evolution, 59: 68-86.

2. Aquino, I.S., C.I., Abramson, A.E.E., Soares, A.C., Fernandez and D. Benbassat, 2004. Classical conditioning of proboscis extension in harnessed Africanized honey bee queens (Apis mellifera L.). Psychological Reports, 94:1221-1231.

3. Bartoszeck, A.B., C.I. Abramson and A.J. Place, 2005. The perception of students in the south of Brazil on the status of psychology as a science. Psychological Reports, 97: 750-756.

4. Morales, B.L., C.I. Abramson, N. Shakuntala, S. Aleixo Junior and A.B. Bartoszeck, 2005. Status of Psychology as a science in northeast Brazil: undergraduate students' perceptions. Psychological Reports, 96: 109-114.
5. Hutz, C.S., B.W., Gomes and S. McCarthy, 2004. Psychology in Brazil: The Road Behind and the Road Ahead. In Stevens, M.J., and D. Wedding, (Eds.). Handbook of International Psychology, Vol. 9: pp: 151-168. New York: Brunner-Routledge.

6. Hayes, N., 1996. What makes a psychology graduate distinctive? European Psychologist, 1: 130-134.

7. Abramson, C.I., D.P. French and S. Locy, 1999. Learning to Use the Contemporary Library: A Laboratory Exercise. In L. Benjamin, B. Nodine, R. Ernst, C. Blair-Broeker (Eds.). Activities Handbook for the Teaching of Psychology, 4: 3-8. Washington, DC: American Psychological Association.

8. Abramson, C.I. and C. Satterfield, 1999. Behavior solutions: Understanding and improving behavior. New Brunswick [CD-ROM], Canada: Silver Fox Development.

9. Malnig, L., 1984. What can I do with a major in ...? Ridgefield, NJ: Abbott Press.

10. Satterfield, C.D. and C.I. Abramson, 1998. The undergraduate psychology club: Possibilities and suggested activities. Teaching of Psychology, 25: 36-37.

11. Page, M.C., C.I. Abramson and J.M. JacobsLawson, 2004. The National Science Foundation research experience for undergraduates program: Experiences and recommendations. Teaching of Psychology, 31: 241-247.

12. Hogan, J.D., 1996. International psychology and the undergraduate curriculum: A personal note. Teaching of Psychology, 23: 44-45.

13. Sexton, C.S. and H. Misiak, 1984. American psychologists and psychology abroad. American Psychologist, 39: 1026-1031. 